\title{
GOLDILOCKS AND THE THREE BEARS: PRÁTICAS E REFLEXÕES SOBRE MOMENTOS DE CRITICIDADE EMERGENTES DA LEITURA DE UMA HISTÓRIA INFANTIL
}

\author{
GOLDILOCKS AND THE THREE BEARS: PRACTICES AND REFLECTIONS ON MOMENTS OF \\ CRITICISM EMERGING FROM READING A STORY BOOK
}

\author{
Luana Cristina Amorim Roja de Lima ${ }^{1}$, Adriana Lúcia Escobar Chaves de Barros ${ }^{1}$ \\ ${ }^{1}$ Universidade Estadual de Mato Grosso do Sul (UEMS), Campo Grande, MS, Brasil \\ roja.Iucristina@gmail.com; chaves.adri@hotmail.com
}

Recebido em 25 nov. 2018

Aceito em 12 abr. 2019

Resumo: Este artigo é um recorte de uma dissertação em andamento e tem como objetivo principal verificar em que medida a leitura e atividades relacionadas à história Goldilocks and the Three Bears ${ }^{1}$ pode contribuir para a emergência de momentos de criticidade em uma aula de Língua Inglesa para crianças. Para tal, nos baseamos nas leituras de autores relevantes na área, como Monte Mór (2013), Rojo (2005), Jordão (2013), Menezes de Souza (2011), entre outros. Trata-se de uma pesquisa qualitativa interpretativa com característica etnográfica que se deu em uma turma de 22 alunos do $3^{\circ}$ ano do Ensino Fundamental de uma escola pública de Terenos - MS. A coleta dos dados foi feita por meio de diário escrito pela professora e pesquisadora deste estudo; produções dos alunos; bem como gravações de áudio. Este estudo destaca uma ferramenta que pode ser utilizada por professores de inglês no Ensino Fundamental e não somente na educação pública. A utilização de textos pertecentes ao universo da criança mostrou-se como um instrumento de diálogo sobre questões cotidianas e reais na sociedade. A emergência de práticas e reflexões sobre Letramentos Críticos esteve presente nas discussões entre professora e alunos, o que comprova a possiblidade de se estabelecer uma leitura crítica com as crianças.

Palavras-chave: Momentos de criticidade. História infantil. Ensino de Inglês.

\begin{abstract}
This article is part of a dissertation in progress and our main goal is to verify the extent to which the reading and activities related to the story book, Goldilocks and the Three Bears, can contribute to the emerging of moments of criticism in an English class for children. For that, we were based on the reading of relevant authors in the area, such as Monte Mór (2013), Rojo (2005), Jordão (2013), Menezes de Souza (2011), among others. This is an interpretative and qualitative research with ethnographic characteristic that occured in a group of 22 students from the third grade of elementary in a public school of Terenos - MS. The collect of data was done by means of a diary, written by the teacher and researcher of this study; students production; as well as audio recording. This study highlights a tool that can be used by English teachers in the elementary school. The use of texts from the child's universe has shown itself as an instrument of dialogue on daily and real issues of the society. The emergence of practices and reflections on Critical Writing was presented in the discussions between teacher and students, which proves the possibility of establishing a Critical Reading with the children.
\end{abstract}

Palavras-chave: Moments of criticism. Story telling. English teaching.

${ }_{1}^{1}$ NAMM, D. GRAEGIN, S. Rapunzel. Sterling children's books: New York, 2013. 


\section{CONSIDERAÇÕES INICIAIS}

Atualmente, na maior parte do país, o ensino de Língua Inglesa para crianças, se limita a instituições particulares e/ou escolas de idiomas, sendo que na rede pública de ensino as aulas de língua estrangeira, doravante LE, têm início a partir do sexto ano do Ensino Fundamental. Garcia (2011, p. 19) afirmou em seus estudos que "todas as modalidades de Ensino de Inglês para Crianças (EIC) mantêm uma característica comum: estão presentes no âmbito privado de ensino".

Opondo-se à afirmação da autora, vemos que mudanças já aconteceram nas modalidades de Ensino de Inglês para Crianças e que alguns municípios no país já oferecem a disciplina nas séries iniciais. Em âmbito nacional podemos citar o município de Londrina, que em 2008 deu início a essa modalidade em todas as escolas municipais londrinenses (CORADIM; TANACA, 2013). No Estado de Mato Grosso do Sul, os municípios de Dourados, Jardim e Terenos já oferecem o Inglês como Língua Estrangeira do $1^{\circ}$ ao $5^{\circ}$ ano do Ensino Fundamental, diferenciando-se de outras regiões do país.

No caso desta pesquisa, o contexto é uma escola pública do município de Terenos - MS. A pequena cidade com estimada população de 20.855 habitantes (IBGE, 2017) implantou o ensino de Inglês nos anos iniciais em 2007, em suas escolas urbanas e rurais. Coradim e Tanaca (2013, p. 141) sugerem que "o ensino de Inglês desde a infância pode desenvolver o gosto pela língua e promover o desenvolvimento da consciência, identidade linguística e cultural", enquanto Rocha (2009; 2010) enfatiza que a língua estrangeira também pode ser um caminho para que a criança assuma um papel mais ativo e mais crítico por meio das práticas transculturais e plurilíngues que podem ser desenvolvidas em sala.

Assim, considerando as mencionadas afirmações o presente estudo tem como objetivo principal apresentar resultados parciais de uma dissertação em andamento, cujo foco é o uso de histórias infantis nas aulas de língua inglesa para o desenvolvimento da criticidade nos alunos, emergente das discussões com os sujeitos da pesquisa.

Os sujeitos desta pesquisa são 22 alunos, com idade média de 9 anos, do $3^{\circ}$ ano de uma escola pública municipal de Terenos, em que a professora é também 
pesquisadora. A coleta dos dados deu-se por meio de diários, produções dos alunos e gravações de áudio e vídeo.

Esta é uma pesquisa de natureza qualitativa e de caráter etnográfico já que o contato direto do pesquisador com o contexto acontece ao longo da coleta e análise dos dados e também de sua análise (ANDRÉ, 2013). Os dados foram analisados de maneira indutiva (BOGDAN; BIKLEN, 1994, p. 50), portanto, não existe uma hipótese completamente definida. Ao contrário, ganha forma na medida em que os processos estão acontecendo e os dados surgindo.

Por ser este artigo o recorte de uma pesquisa em andamento, apresentamos e analisamos aqui os dados coletados a partir do contar de uma das histórias infantis trabalhadas em sala de aula, ou seja, Goldilocks and the Three Bears, em português, Cachinhos de Ouro. Abordamos também alguns aspectos teóricos relacionados aos Letramentos Críticos, tendo em vista a relevância desses conceitos teóricos para o desenvolvimento da pesquisa.

\section{LETRAMENTOS CRÍTICOS: NOÇÕES E CONCEITOS}

Segundo Jordão (2016, p. 43), o Letramento Crítico é uma perspectiva educacional "construída a partir de uma visão de mundo pós-moderna". Stuart Hall (2011, p. 13) trata do sujeito pós-moderno, como aquele que assume "identidades diferentes em diferentes momentos, identidades que não são coerentes ao redor de um "eu" coerente.", além de ter a identidade móvel e instável como característica. Diante do exposto, podemos inferir que o Letramento Crítico contribui para refletirmos sobre as identidades dos sujeitos e como elas são influenciadas pelos (con)textos com os quais entram em contato. Luke (2004) apresenta a criticidade como uma ferramenta usada para construir identidades e, ao pensar no contexto de pós-modernidade, reconstruí-las em diferentes discursos.

O termo Letramento se tornou um expoente relativamente recente em pesquisa no Brasil, pois como constatado por Reis (2008), o conceito se tornou de fato expressivo no país a partir de 2004, tendo aparecido pela primeira vez em estudos acadêmicos no ano de 1991. Segundo Soares (2009), esse termo aparece no país pela primeira vez em 1986 no livro No mundo da escrita: uma perspectiva 
psicolinguística, escrito por Mary Kato; e em seguida em 1988 e 1995 em Os significados do Letramento por Ângela Kleiman. Soares (2009, p. 34-35) justifica que "o termo letramento surgiu porque precisávamos de um nome, um fenômeno que não existia antes, ou, se existia, não nos dávamos conta dele, não tínhamos um nome para ele.".

Letramento, segundo Magda Soares (2010), surgiu de literacy, que vem do latim e significa litera (letra), e seu sufixo cy (estado ou ser). A partir desse conceito, compreendemos que o termo literacy, implica o fato de que o indivíduo além de ler e escrever, também se apropria das práticas sociais e culturais que acompanham os processos de leitura e escrita, ou seja, o resultado do processo de aprendizagem da leitura e escrita é o estado da ação ou a condição que tem um grupo social ou uma pessoa, como consequência, de poder se apropriar da escrita. Consoante a isso, Jesus e Carbonieri (2016, p. 13) afirmam que:

Nos últimos anos, a noção de letramentos vem sendo entendida como uma prática social plural e situada que reflete valores culturais, políticos, ideológicos e linguísticos de determinado grupo social, conduzindo os aprendizes à construção de sentidos e à criação de seus próprios textos.

Dessa maneira, vemos uma pluralização do termo "letramento" e seu uso em diferentes perspectivas, como é o caso dos "multiletramentos", "novos letramentos", "letramento crítico", "visual" e "letramento digital". No que diz respeito à palavra "crítico", existe uma variedade de conceitos abordados por diferentes autores. Monte Mór (2013) destaca alguns desses pesquisadores, como Gikandi (2005), que distingue criticism e critique, cujas traduções para o português convergem para uma mesma palavra - crítica. Segundo o autor, criticism aponta para a crítica por meio de avaliação, cujos critérios são definidos a partir de um conhecimento especializado sobre o objeto ou sujeito avaliado. Diferentemente disso, critique não demanda especialização ou conhecimento prévio, pois tem relação com as percepções sociais, tornando-se assim uma crítica social.

O estudo de Gikandi tem fundamentação em Leavis (1969) ao advogar que "crítica e cultura estão intrinsecamente relacionadas" (MONTE MÓR, 2013, p. 34) e mais tarde Vattimo (1990) sustenta tais perspectivas ao caracterizar criticism como interpretação e avaliação especializadas; e critique como análise social. Outro importante teórico mencionado por Monte Mór é Barthes (1999) que afirma que "o 
objeto do crítico não é o mundo, mas o discurso de um outro" (MONTE MÓR, 2013, p. 35). A distinção feita por ele corrobora com a de Gikandi, pois o mesmo define dois tipos de crítica: a universitária e a ideológica. A primeira delas segue um modelo positivista de objetividade e rigor enquanto a segunda é subjetiva, com interpretações ideológicas.

Nas palavras de Rojo (2012, p. 28) letramento crítico é: "transformar o consumidor acrítico em analista crítico". Isto quer dizer que quando um estudante está diante de um texto e é incentivado a lê-lo criticamente, ele tem a oportunidade de se tornar um crítico sem que precise ser especialista no assunto. O que ocorre é uma crítica social e uma crítica sobre si mesmo, sobre aqueles com quem interage e sobre o lugar em que está no mundo.

O uso do termo "crítico" tem sido recorrente em diversas áreas e alguns autores se dedicam em explicar e contextualizar o seu sentido. Lankshear e Mc Laren (1993), por exemplo, entendem que quando tentamos mudar a compreensão que temos do mundo, estamos sendo críticos; e de maneira similar, Jordão (2016) estabelece que ser crítico significa reconhecer e entender como você está no mundo, seu ser, seu ver e seu fazer. É também entender essas mesmas formas de estar no mundo nos outros sujeitos e nos textos que produzem, além de, a partir dessa visão de si e do outro, poder construir, destruir e reconstruir suas próprias formas de estar no mundo.

Pensando nesses conceitos teóricos acerca do que caracteriza um sujeito como crítico, nos deparamos com as seguintes indagações: onde aprendemos a ser críticos, se é que isso pode ser aprendido? Quem forma um sujeito crítico? A escola é lugar para isso? O professor de língua estrangeira é responsável por tal ensinamento? Pashby (2008, p. 9) fala sobre "encorajar os jovens a desenvolver uma consciência de si mesmos como cidadãos do mundo.", sendo esse um objetivo da escolarização desses jovens. Além disso, Vetter (2008, p. 110) destaca que "os jovens de hoje precisam ser empoderados para uma atitude crítica".

Diante disso, entendemos que a escola e o professor precisam auxiliar os estudantes no desenvolvimento de sua criticidade, possibilitando um olhar para si mesmos, para o outro e para o diverso. No entanto, nessa perspectiva de que o professor indica um caminho para que o estudante se torne crítico, podemos cair na 
armadilha de que meu aluno só é crítico quando reflete sobre aspectos que gostaríamos que ele refletisse (MACIEL, 2014).

Jordão (2017) afirma que não é papel do professor dizer o que ou como o estudante deve ler um texto. Para a autora seria mais pertinente "ampliar seu leque de procedimentos interpretativos e visões de mundo, para poder ajudar os alunos a ampliarem também os seus" (JORDÃO, 2017, p. 201). Em outros momentos Jordão aponta que o professor precisa "sair da sua posição de detentor da verdade e fonte de conhecimento" (2016, p. 47) e assim reconhecer o aluno como alguém que também produz sentido e que constrói saberes. Essa relação professor-aluno que hierarquiza e diferencia os conhecimentos desses dois sujeitos é também uma construção social, que pode ser questionada e redefinida.

Da mesma maneira, existe uma construção histórica sobre aquilo que é valorizado ou não na escola. Jordão (2016) afirma que a sala de aula é um espaço onde a diversidade, a pluralidade, os conflitos e as desigualdades são constantes e influenciam diretamente na construção de sentidos que se realizam nesse ambiente. Porém, no tocante ao letramento crítico, essas características, que normalmente são vistas como negativas e/ou barreiras a serem eliminadas, são tomadas como espaços produtivos para a construção de conhecimentos e para a relação com o outro. A sala de aula não é uma preparação para o mundo ou para o que o aluno irá enfrentar na vida, como tradicionalmente ouvimos. Ao contrário disso, a sala de aula é parte do mundo, é parte da vida, é lugar para problematizar, atuar, reconhecer-se e reconhecer o outro, as diferentes realidades sociais e como tais realidades estão ligadas aos loci de enunciação de cada sujeito.

Outro aspecto importante citado por Jordão é o lugar do saber e dos conhecimentos quando tratamos de letramento crítico, sendo eles vistos como "ideológicos, incompletos, deslizantes, múltiplos e relativos; sempre passíveis de contestação, questionamentos e transformação" (JORDÃO, 2013, p. 81). Segundo a autora, para que haja o engajamento social faz-se necessário desenvolver, em si e nos estudantes, o que ela chama de "atitude de atenção" para com nossos valores e nossas crenças. Nessa atitude de atenção está implícito que tudo aquilo que valorizamos e acreditamos é situado e contextualizado pelo repertório sociocultural e comunidade de cada sujeito. 
A relatividade, na visão do LC, implica perceber-se reflexivamente como alguém que constrói sentidos e os valora a partir de determinados quadros de referência, a partir de visões de mundo específicas, e não a partir de supostas verdades absolutas ou essencialidades ligadas à natureza das coisas e das pessoas. (JORDÃO, 2016, p. 46)

O que chamamos de repertório sociocultural dialoga com o que Bhabha (1994) chama de lócus de enunciação; e Duboc (2016) ressalta que o letramento crítico prioriza a construção de sentido, construção essa que ocorre com base no lócus. Duboc também aponta para a problematização como parte importante do fazer do letramento crítico, além da percepção do eu e do outro, de como eu leio e de como o outro o faz. No que diz respeito aos sentidos, Jordão (2016) afirma que eles são construídos previamente pelo autor, mas são concretizados no ato de leitura/compreensão, pois ao ler um texto (seja ele oral, escrito ou multimodal) o leitor mobiliza diversos conhecimentos e recursos interpretativos para conferir sentidos ao enunciado com o qual está em contato.

Consoante a essas asserções, Janks (2016) valida que os sentidos que queremos elaborar dependem do que o leitor irá inferir e essa compreensão depende também do lugar onde esse leitor está situado. Da mesma maneira, Maciel (2017, p. 108) reforça que "o letramento crítico estaria comprometido em abordar como a relação entre leitor e autor, como sujeitos sociais que possuem percepções a partir dos seus contextos sócio-históricos, possui efeito no ato interpretativo". É nessa relação de autores e leitores que podemos notar uma mudança da noção de leitura crítica para o letramento crítico atualmente. O foco não está mais nas verdades ocultas e nas intenções do autor, uma vez que existe uma preocupação com o modo de ler o texto, pois essa leitura também está cercada de discursos e ideologia, afinal quem lê não está neutro nesse processo.

O ato da leitura torna-se crítico no momento em que a "diferença" é percebida e estabelecida entre o autor e o leitor que constroem significados de acordo com os valores de seus próprios contextos e, assim, tornam-se críticos não só do contexto do Outro, mas também de seu próprio contexto de produção. (MATTOS, 2017, p. 175)

A relação de alteridade existente no letramento crítico está relacionada ao que Freire (2002/2005) chama de estar com o mundo. Compreender o outro, seus modos de ler e escrever é também compreender seu próprio eu; e isso é estar no e 
com o mundo de maneira crítica. Além do olhar sensível para o outro, o letramento crítico também colabora com a atenção para a diversidade. Duboc (2016, p. 62), por exemplo, enxerga o LC como uma:

perspectiva educacional muito pertinente nos dias de hoje, em que toda diversidade social, étnica, racial, de gênero e sexualidade e de condições físicas outrora velada clama por um sujeito ético e responsável, um sujeito que reconhece a diferença, e, acima de tudo, sabe com ela conviver. (DUBOC, 2016, p. 62)

O contato dos sujeitos desta pesquisa com a história infantil Goldilocks and the Three Bears possibilitou tanto a percepção dos alunos acerca do eu e do outro, quanto um olhar para a diversidade do mundo em que vivemos hoje. Ao comparar a família retratada na história com a sua própria família, os alunos perceberam a relação de alteridade. Quando abordamos a diversidade de famílias na sociedade atual, os alunos tiveram a oportunidade de reconhecer as diferenças e respeitá-las. O respeito foi observado pelos comentários que faziam e exemplos que traziam para a discussão.

Sobre os objetivos do letramento crítico, Mattos (2017) aponta o desenvolvimento da consciência crítica como um objetivo instrucional e a cidadania participativa (MATTOS, 2011) como uma das principais finalidades dessa perspectiva educacional.

Em uma tentativa de apontar algumas (in)definições acerca de letramento crítico, apresentamos ao leitor um quadro de referência a respeito de como alguns autores conceituam o termo. Justificamos a elaboração da tabela apropriando-me de uma constatação de Duboc (2016, p. 75) sobre a importância de entender o "conceito de letramento crítico, uma vez que por vezes encontramos no discurso educacional um certo uso excessivo e indiscriminado do termo "crítico". Em conformidade à afirmação da autora, acreditamos também que por vezes encontramos pesquisas em que a definição de letramento crítico permanece muito similar à pedagogia crítica de Freire ou à leitura crítica, como se fossem a mesma coisa (JORDÃO, 2013). Sendo assim, buscamos delimitar a seguir o que alguns autores definem como letramento crítico ou não. 


\begin{tabular}{|l|lr|}
\hline \multicolumn{1}{|c|}{ O que não é letramento crítico: } & \multicolumn{3}{|c|}{ O que é letramento crítico: } \\
\hline $\begin{array}{l}\text { Técnica ou um conjunto de estratégias. } \\
\text { (WOOLDRIDGE, 2001) }\end{array}$ & $\begin{array}{l}\text { Uma perspectiva educacional que } \\
\text { envolve determinadas práticas ou } \\
\text { abordagens em uma aula, } \\
\text { contextualização sociopolítica das } \\
\text { práticas de letramento. (WOOLDRIDGE, } \\
2001)\end{array}$ \\
\hline $\begin{array}{l}\text { Letramento crítico não é o mesmo que } \\
\text { leitura crítica. (DUBOC, 2016) }\end{array}$ & $\begin{array}{l}\text { Agência social, agir sobre o local onde } \\
\text { está inserido. (JANKS, 2016) }\end{array}$ \\
\hline $\begin{array}{l}\text { Já não é ler que escreveu o texto. } \\
\text { (MENEZES DE SOUZA, 2011) }\end{array}$ & $\begin{array}{l}\text { Atitude crítica de ler se lendo. } \\
\text { (MENEZES DE SOUZA, 2011) }\end{array}$ \\
\hline
\end{tabular}

Fig. 1: (In)definições de letramento crítico (MENEZES DE SOUZA, 2011).

Com base nos autores citados, é possível retomar a ideia de que, apesar do letramento crítico ter certa influência da pedagogia e leitura críticas, as práticas e estudos em LC apontam para um distanciamento da leitura de intenções e ideologias. Não é mais objetivo do LC desvendar verdades 'ocultas' nos textos. Não é ler criticamente as intenções do autor, mas ao contrário disso, é pensar em como lemos e porque fazemos as leituras dessa maneira, é uma leitura de si mesmo por meio da leitura do outro.

Enfim, de acordo com a nossa concepção, o letramento crítico é um conjunto de princípios educacionais que têm por objetivos, desenvolver as práticas discursivas de construção de sentidos, bem como encorajar as leituras alternativas e as tomadas de posições sobre elas, para que o sujeito possa questionar e criticar sua vida cotidiana e a sociedade em que está inserido.

\section{GOLDILOCKS AND THE THREE BEARS}

Como já apresentado anteriormente, este artigo é um recorte de uma dissertação em andamento e para tanto os excertos e as produções relacionadas a uma das histórias infantis contada aos alunos, serão aqui analisadas. A história escolhida foi Goldilocks and the Three Bears. A coleta dos dados aconteceu com os 
22 alunos do $3^{\circ}$ ano do Ensino Fundamental de uma Escola Municipal, localizada no município de Terenos, Mato Grosso do Sul.

A professora e também pesquisadora deste estudo fez a escolha desta história infantil baseando-se em três fatores: 1) é uma história que provavelmente os alunos já teriam lido ou ao menos ouvido falar em sua língua materna; 2) é uma oportunidade para relembrar o vocabulário de family com os alunos por meio da leitura; 3) poderíamos pensar criticamente sobre a temática familiar ao longo da história e com as produções pós-leitura.

A seguir, apresentamos alguns excertos transcritos a partir das gravações de áudio feitas ao longo da leitura do livro, assim como a análise dos mesmos.

P: So, there were three bears: Pappa bear, Mamma bear and Baby bear. They were a family.

(Enquanto isso, a professora mostra as imagens no livro)

P: A family de vocês é parecida com essa aqui?

Alguns dizem que sim, outros dizem que não.

A3: A minha é.

P: A sua é João Pedro?

A3: Sim. Sou eu, minha mãe e meu pai. Mas minha mãe está grávida, daqui um tempo não vai ser mais assim.

P: Quem falou que não é igual?

(..)

A4: Eu moro com meu pai e eu. Mas a família é meu pai, meu irmão, minha irmã, minha outra irmã. Minha mãe não mora comigo, é meu pai que me cuida.

P: Quem mais?

A5: Eu, minha mãe, meu tio, meu primo, minha vó e meu vô.

P: Acho que a gente podia tentar falar em inglês, não é? My mother, my brother...

A6: My brother, my mother, my grandmother e meu primo.

A7: My mother, my brother, my father, só que meu pai não mora na mesma casa, ele mora em outra casa, mas mesmo assim é minha família.

P: Sim. Claro.

P: Então, essa aqui é a family dos bears, mas nem todas as families precisam ser como a deles, cada um tem a sua family não é mesmo?

A9: Sim!

P: Aqui na sala, como nós vimos, tem alguns que não moram com o father ou não moram com a mother. Tem gente que mora na mesma casa com grandmother, grandfather. Tem gente que não tem nem brother, nem sister. Assim como o Baby bear, por exemplo, ele não tem brother ou sister, ele é filho único.

O primeiro aspecto a ser analisado neste excerto é que constantemente os alunos e a professora transitam entre a língua materna e a língua alvo e a professora parece perceber isso apenas no final do diálogo, quando pede aos alunos que tentem falar as palavras relacionadas aos seus familiares em inglês.

Além disso, podemos observar que a discussão promovida neste excerto está relacionada aos diferentes tipos de família, o que vai ao encontro ao que advoga 
Menezes de Souza (2011, p. 128): "Preparar aprendizes para confrontos com diferenças de toda espécie se torna um objetivo pedagógico atual e premente, que pode ser alcançado através do Letramento crítico.”.

Neste momento, vale lembrar o objetivo inicial da pesquisa, isto é, verificar a possibilidade de reflexões e práticas de Letramentos Críticos a partir da leitura de Goldilocks and the Three Bears. Verificamos com o diálogo entre a professora e os alunos que essas reflexões acontecem breve e superficialmente, sem que os alunos consigam aprofundar-se no assunto. Em outro momento da leitura, os alunos conseguiram refletir criticamente sobre outra prática das personagens. Vejamos:

P: Então, cada um tinha sua bed não é? Big, medium sized and small bed. Isso é diferente?

A11: Não.

A3: Mas a mãe e o pai não dormem juntos.

A12: E também cada um tem um tamanho de cama. Cada cama de uma cor também.

P: Mas e porque que o Pappa bear tem que ser sempre o maior - big chair, big bed?

A11: Ah! Porque ele é o 'mais grande'.

A13: Ou de certo por que ele é homem.

A14: Eu acho que não!

A4: Eu acho que isso é racismo!

P: Racismo? Mas racismo é o preconceito com relação à cor da pele. Racismo não é. Você acha que é preconceito?

A4: Isso!

P: Mas preconceito em relação ao que? Por que ele é o homem, ele tem que ter tudo maior?

A4: É e isso é preconceito.

P: Mas você acha isso certo Nathália?

A4: Não.

P: Mas como seria certo então?

A11: Não, mas não é preconceito e ao mesmo tempo é.

P: Porque?

A11: Porque, é porque ele é homem. Eu não sei explicar.

A15: Como se ele fosse o superior.

P: Sim. Eu entendi. Mas e vocês concordam com isso?

A4: Não. Nada a ver. Porque tem famílias que só tem a mãe.

$E$ a mãe faz o papel de pai. $E$ aí a mãe que é superior.

A11: É isso que eu quis dizer. Queria falar igual a Nathália na verdade.

P: Tá. Então encontramos aqui uma coisa que talvez poderia ser diferente na história. Como vocês acham que poderia ser?

A15: A mãe tinha que ter o mesmo espaço que o pai. Ou então eles podiam dormir juntos.

P: Então, vocês acham que podia ser a mesma cama e o mesmo espaço para os dois. É isso? (Alguns concordam que sim)

Analisando esse segundo diálogo podemos perceber que os alunos se aprofundaram um pouco mais ao pensar criticamente sobre os pertences do papai urso. Quando a professora chama a atenção dos alunos para o fato de que tudo do 
papai urso é maior e questiona o motivo, a primeira razão apontada é o tamanho dele, pois é o maior da família.

Entretanto, logo em seguida uma aluna aponta para a questão da desigualdade entre homens e mulheres. Está explicito no diálogo que ela não usa essas palavras e até mesmo se confunde com os termos racismo e preconceito. Isso pode ser justificado pela própria idade dos sujeitos da pesquisa, já que os mesmos têm entre 8 e 10 anos. Mesmo assim, é possível perceber um momento em que os Letramentos Críticos emergem no diálogo dos alunos e eles passam a refletir sobre os papéis e as relações entre homens e mulheres na sociedade. De acordo com Menezes de Souza (2011, p. 136):

a produção de significação não é um ato aleatório e voluntarioso de indivíduos independentes: pelo contrário, a produção de significação é um ato complexo sócio histórico e coletivo no qual cada produtor de significação pertence simultaneamente a diversas e diferentes comunidades que constituem um conjunto social coletivo.

A afirmação acima justifica o fato de que ao longo do diálogo entre os alunos, eles estabelecem uma atitude colaborativa e cada sujeito traz suas experiências de mundo para chegarem a uma conclusão. Vemos que existe uma tentativa da parte das crianças de diferenciar as palavras racismo e preconceito, quando na verdade a intenção deles é questionar a superioridade do papai urso em relação aos outros membros da família.

Ao final da discussão eles puderam pensar em algo que gostariam que fosse diferente na história. Após as tentativas de expressar seus pensamentos sobre essa desigualdade, eles refletiram também sobre relações comuns em nossa sociedade, como o fato de que se uma mãe cuida da casa e dos filhos sozinha, ela faz o papel de pai.

Por fim, cabe analisar a fala da professora quando pergunta se a aluna acha determinada atitude certa e também questiona como seria o certo. É necessário observar que o uso de termos como certo ou errado não seriam recomendados em momentos de discussões como esta. De certa maneira, ao questionar "E você acha isso certo?" a professora está sugerindo que a resposta da aluna seja negativa, influenciando sua opinião. De acordo com o diário da professora, após a leitura do livro e a discussão sobre os diferentes tipos de família, cada criança teve a 
oportunidade de redesenhar a capa do livro, imaginando como seria se a família do livro fosse a própria família deles:
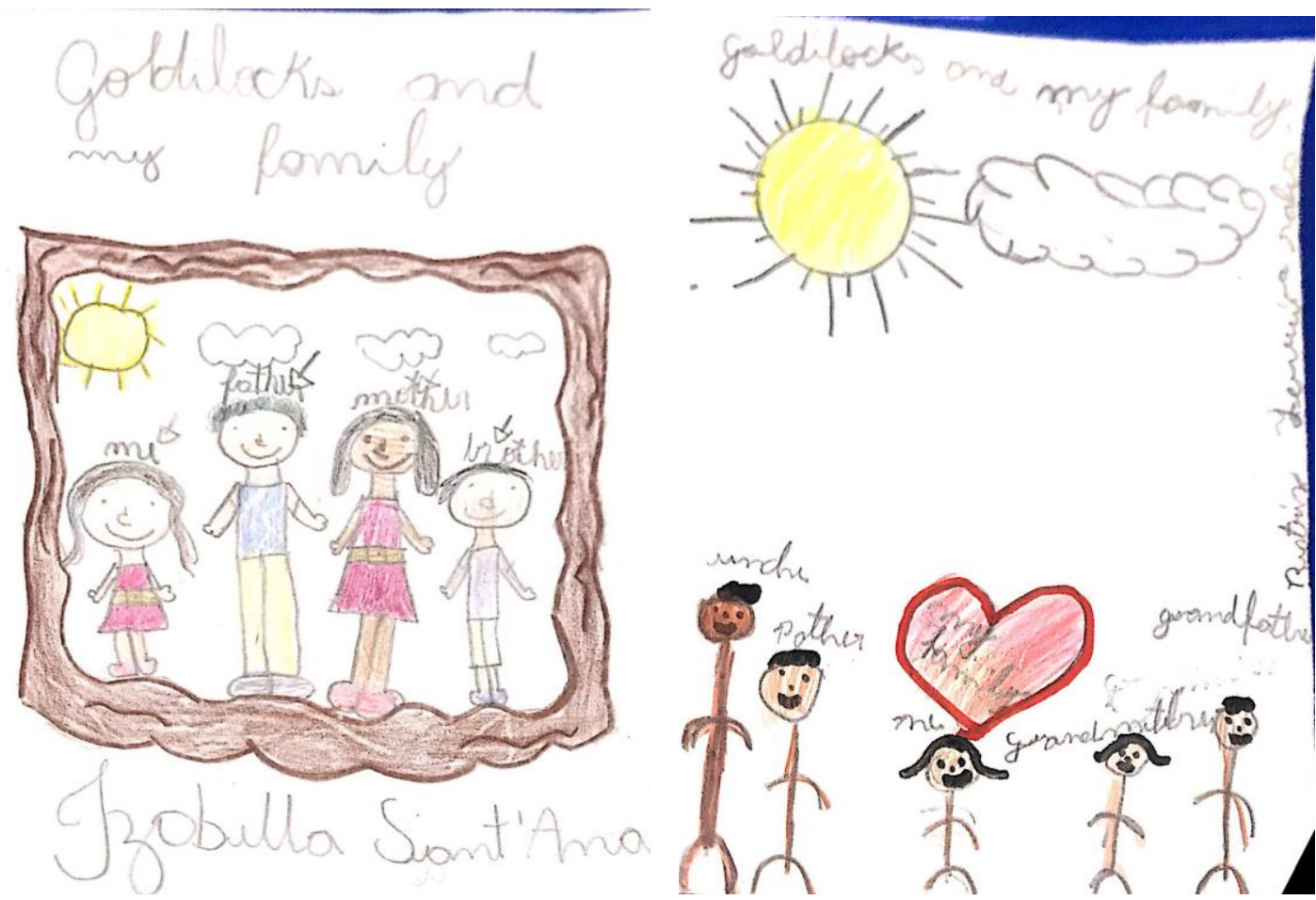

Fig. 2: Produções dos alunos - redesenhando a capa do livro.

Em suma, a análise dos dialógos entre professora e alunos mostrou que existe a possibilidade de que práticas e reflexões de Letramentos Críticos sejam emergentes nas aulas de inglês desde as séries iniciais. Ainda que as discussões não sejam tão aprofundadas, é possível que os alunos estejam em contato, desde cedo, com uma leitura mais crítica dos textos, tendo as histórias infantis como instrumentos para tal prática.

\section{CONSIDERAÇÕES FINAIS}

O ensino de língua inglesa nas séries iniciais do Ensino Fundamental é uma iniciativa de alguns municípios do país. Tal iniciativa sem dúvida pode trazer muitos benefícios para o desenvolvimento linguístico e cultural dos alunos.

A priori, podemos inferir que quando o aluno tem o contato com a língua estrangeira desde o início de sua escolarização, ele tem mais tempo para se 
familiarizar com o idioma, sem que seja algo completamente desconhecido quando ele ingressa nas séries finais do Ensino Fundamental.

Outrossim, essa é uma chance para que os alunos tenham contato com outra cultura desde cedo, que aprendam aspectos relacionados ao mundo e a globalização. Monte Mór (2013) aponta para o fato de que as legislações educacionais já estabelecem a necessidade de que a educação se preocupe com o desenvolvimento de cidadãos críticos e as aulas de língua podem oferecer mais uma oportunidade para que os alunos, desde cedo, leiam textos (não apenas escritos) de maneira mais consciente.

Dessa forma, este estudo destaca uma ferramenta que pode ser utilizada por professores de inglês nos anos iniciais do Ensino Fundamental e não somente na educação pública. A utilização de textos pertecentes ao universo da criança mostrou-se como um instrumento de diálogo sobre questões cotidianas e reais na sociedade.

Sendo assim, a emergência de práticas e reflexões sobre Letramentos Críticos esteve presente nas discussões entre professora e alunos, o que comprova a possiblidade de se estabelcer uma leitura crítica com as crianças. Ainda que tais discussões não sejam tão aprofundadas, elas já preparam o sujeito para o pensamento crítico e os prepara para outros momentos da vida, dentro e fora da escola, em que precisarão desta criticidade.

\section{REFERÊNCIAS}

ATWELL, N. At the reading zone. USA: Scholastic, 2007.

BOGDAN, R. C.; BIKLEN, S. K. Investigação qualitativa em educação: uma introdução a teoria e aos métodos. Portugal: Porto Editora, 1994.

CORADIM, J. N.; TANACA, J. J. C. Inglês nas Séries Iniciais e Inglês no Contexto de Língua Franca: Contribuições Reflexivas para Processos de Formação Continuada e Ensino-Aprendizagem. Gláuks Online, Viçosa, v. 13, n. 1, p. 135-155, 2013.

CORADIM, J. N. Leitura Crítica e Letramento Crítico: idealizações, desejos ou (im)possibilidades. 2008. Dissertação (Mestrado em Estudos da Linguagem) Centro de Letras e Ciências Humanas, Universidade Estadual de Londrina, Londrina, 2008. 
GARCIA, B. R. V. Quanto mais cedo melhor (?): uma análise discursiva do ensino de inglês para crianças. 2011. Dissertação (Mestrado em Letras) - Faculdade de Filosofia, Letras e Ciências Humanas, Universidade de São Paulo, São Paulo, 2011.

JORDÃO, C. M. Abordagem comunicativa, pedagogia crítica e letramento crítico farinhas do mesmo saco? In: ROCHA, C. H.; MACIEL, R. F. Língua estrangeira e formação cidadã: por entre discursos e práticas. Campinas: Pontes Editores, 2013b. p. 69-90.

MENEZES DE SOUZA, L. M. T. Para uma redefinição de Letramento Crítico: conflito e produção de significado. In: MACIEL, R. F.; ARAÚJJO, V. de A. (org.). Formação de professores de línguas: ampliando perspectivas. Jundiaí: Paco Editorial, 2011. p. $128-140$.

MONTE MÓR, W. Crítica e Letramentos Críticos: reflexões preliminares. In: ROCHA, C. H.; MACIEL, R. F. (org.). Língua estrangeira e formação cidadã: por entre discursos e práticas. 1. ed. Campinas: Pontes Editores, 2013. v. 1. p. 31-59.

MOTTA, A. P. F. O letramento crítico no ensino/aprendizagem de Língua Inglesa sob a perspectiva docente. Londrina: Programa de desenvolvimento educacional do Paraná, 2008.

ROJO, R. Gêneros do discurso e gêneros textuais: questões teóricas e aplicadas. In: MEURER, J. M.; BONINI, A.; MOTTA-ROTH, D. Gêneros: teorias, métodos, debates. São Paulo: Parábola Editorial, 2005.p. 184-207.

. Pedagogia dos multiletramentos; diversidade cultural e de linguagens na escola. In: ROJO, R.; MOURA, E. (org.) Multiletramentos na escola. São Paulo: Parábola Editorial, 2012.p. 11-32.

SANTOS, R. R. P. dos; IFA, S. O Letramento crítico e o ensino de inglês: reflexões sobre a prática do professor em formação continuada. The ESPecialist, Maceió, v. 34, n. 1, , 2013. p. 1-23

TONELLI, J. R. A. Histórias infantis no ensino da língua inglesa para crianças. 2005. Dissertação (Mestrado em Estudos da Linguagem). Centro de Letras e Ciências Humanas - Universidade Estadual de Londrina, Londrina, 2005.

\section{Sobre as autoras}

\section{Luana Cristina Amorim Roja de Lima}

Graduada em Letras pela Universidade Católica Dom Bosco (2016) e Mestranda em Letras Linguagem e Literatura, área de concentração Linguística Aplicada, pela Universidade Estadual de Mato Grosso do Sul. Foi bolsista do Programa de Desenvolvimento Profissional de Professores de 
Inglês nos Estados Unidos (PDPI / CAPES) no ano de 2018 pela Universidade Estadual da Georgia em Atlanta, EUA. Atua como professora de Língua Inglesa na rede municipal de ensino de Terenos, Mato Grosso do Sul e na rede privada em curso de idioma (Cambridge English Course) no mesmo município. Tem interesse em pesquisas a respeito do ensino de inglês para crianças em contexto público em estudos de Letramento Crítico e Multiletramentos.

\section{Adriana Lúcia Escobar Chaves de Barros}

Possui Pós-Doutorado em Letras Modernas pela USP (2016-2017). É Doutora em Estudos da Linguagem pela PUC-Rio (2010). Mestre em Administração de Empresas com especialização em Marketing pelo IAG Escola de Negócios da PUC-Rio (2006). Diplomada no curso de pós-graduação em Management (MBA) pelo IAG Escola de Negócios da PUC-Rio (2003). Diplomada no curso de pós-graduação em Metodologia do Ensino da Língua Inglesa (DOTE - Diploma for Overseas Teachers of English, RSA) pela Universidade de Cambridge, Inglaterra (1994), adquirindo o título de Royal Society of Arts. Graduada em Letras Português-Inglês Licenciatura Plena pela PUC-Rio (1984). Atualmente é professora efetiva da Universidade Estadual de Mato Grosso do Sul, ministrando aulas nos cursos de graduação e de pós-graduação stricto sensu do Mestrado Acadêmico e Profissional em Letras. Foi tesoureira da ALAB (Associação Brasileira de Linguística Aplicada) no biênio 2014-2015. Foi professora da Universidade Anhanguera-Uniderp, em Campo Grande, Mato Grosso do Sul, na graduação dos cursos de Administração e Publicidade e Propaganda e na pós-graduação lato sensu no curso de MBA (2010-2011), e assumiu a coordenação do curso de Publicidade e Propaganda em 2011. Trabalhou na Cultura Inglesa Rio (1986-2009), onde foi professora, coordenadora pedagógica e gerente de filial (1993-2009). Foi professora de classe de alfabetização, de inglês no Ensino Fundamental e em instituições particulares de Língua Inglesa (1979-1998). Tem experiência profissional nas seguintes áreas: Estudos da Linguagem com ênfase em Linguística Aplicada e Sociolinguística; Administração Escolar, com ênfase em Gestão Organizacional e Gestão de Pessoas; e Administração de Empresas, com ênfase em Comunicação Empresarial, Marketing, Liderança e Negociação. Atualmente, suas áreas de interesse são: Sociolinguística Interacional/Variacionista e Linguística Aplicada, com foco em Ensino de Línguas, Formação de Professores, Línguas de Comunidades Minoritárias e (De)colonialidade, Fronteiras, Língua, Cultura e Identidade. 